\title{
Field Measurement and Mechanical Analysis of Height of the Water Flowing Fracture Zone in Short-Wall Block Backfill Mining beneath the Aquifer: A Case Study in China
}

\author{
Yun Zhang, Shenggen Cao $\mathbb{D}$, Tong Wan, and Jijun Wang \\ State Key Laboratory of Coal Resources \& Safe Mining, School of Mines, China University of Mining \& Technology, \\ Xuzhou 221116, China \\ Correspondence should be addressed to Shenggen Cao; yun11300@126.com
}

Received 29 June 2018; Revised 3 September 2018; Accepted 13 September 2018; Published 4 October 2018

Guest Editor: Wen Wang

Copyright (c) 2018 Yun Zhang et al. This is an open access article distributed under the Creative Commons Attribution License, which permits unrestricted use, distribution, and reproduction in any medium, provided the original work is properly cited.

\begin{abstract}
Short-wall block filling mining (SBBM) technology has become an effective way to recover coal resources beneath the aquifer, which are unsuitable, or cannot be used by long-wall mining, such as corner coal pillars, industrial square pillars, and irregular coal blocks as well as the coal beneath buildings, railways, and water bodies. The SBBM method can not only enhance the recovery ratio but also provide a solution for the environment problems associated with gangues on the surface. However, whether the height of water flowing fractures will reach to the aquifer to cause water loss during SBBM has always been a key problem. Therefore, based on the theory of elastic foundation beam and SBBM characteristics, a mechanical model for calculating the height of a water flowing fracture zone in the overlying strata of SBBM was established, and this model calculated that the height of the water flowing fracture zone was $27.0 \mathrm{~m}$ in the experimental working face, and the height of the water flowing fracture zone was measured as $26.8 \mathrm{~m}$ according to washing fluid loss in the hole, core damage analysis, and drilling TV imaging detection. The comparison results demonstrated that the calculated value almost fit well with the fieldmeasured data, validating the accuracy of the proposed mechanical model, while the predicted value $(48.7 \mathrm{~m})$ in the Regulations of coal mining under building, railways and water-bodies deviates greatly from the measured results. This reveals that the prediction formula in Regulations is not effective in predicting the height of the water flowing fracture zone in SBBM. The present research results are of great significance to further enhancing the recovery ratio of coal resources and improving the water-preserved mining theory.
\end{abstract}

\section{Introduction}

During the coal mining process, overlying strata experience significant mining-induced movements and deformation, inevitably causing the collapse and fracturing of strata and forming a lot of fractures [1-3]. Many water flowing channels, also referred to as water flowing fracture zone, are formed once these fractures are interconnected. As shown in Figure 1, when this water flowing fracture zone develops towards the aquifer or water-rich regions on the surface, serious water loss can be triggered, thereby leading to the deficiency of water resources and further inducing a series of environmental problems such as land desertification, sparse ground vegetation, and dry-up of streams [4-6]. Meanwhile, because of large-scale mining for a long time and some deployment patterns during mining in long-wall faces, massive gangues are discharged and heaped up after the mining [7-10] (Figure 1), bringing severe challenges on the mine's ecological environment and results in the waste of vast residue coal resources such as a lot of corner coal pillars and irregular blocks $[11,12]$. Destruction of the environment and waste of coal resources are facing serious problems that threaten the government's strategy of sustainable development. To address these problems, an effective environmentally friendly mining 


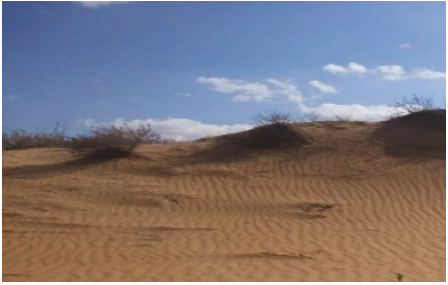

(a)

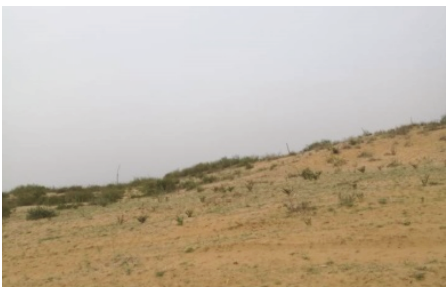

(c)

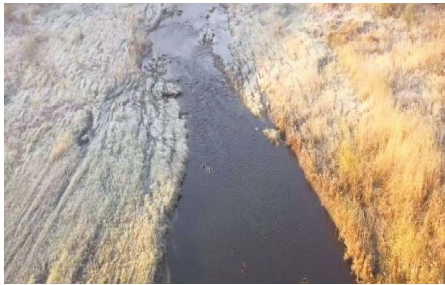

(b)

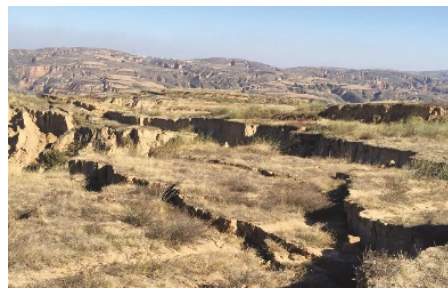

(d)

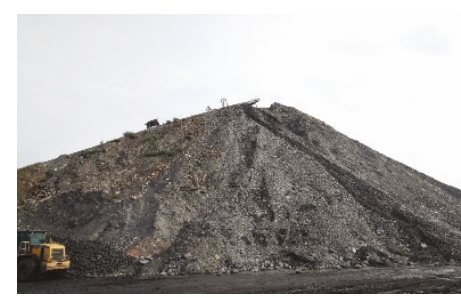

(e)

FIGURE 1: Coal-mining-induced severe environmental problems. (a) Land desertification; (b) dry-up of streams; (c) sparse ground vegetation; (d) development of fractures towards the ground; (e) stacking of gangues.

method, namely, short-wall block backfill mining (SBBM) method, was proposed in this study. This strategy not only enhanced the recovery ratio of coal mines and reduced gangue discharge but also avoided further mining-induced water loss.

Currently, a great deal of research has been carried out on the protection of underground and ground water resource. Sun and Miao [13] and Miao et al. [14] put forward the concept and the principle of water-resisting key strata and systemically analyzed the basic mechanical properties of water-resisting key strata and the distribution of interconnected fractures. Xu et al. [15-17] investigated the effect of key strata on the development height of the water flowing fracture zone in depth and proposed a new method for predicting the height of the water flowing fracture zone based on the position of key strata. Some scholars also extensively examined the block caving mining method. Based on the research results of the roof movement, Zhou $[18,19]$ systematically analyzed the strata behavior regularity in block caving mining. Cao et al. [20] examined the mechanism of the instability of protective coal pillars in the block caving mining process based on the theory of cusp catastrophe. However, related theories regarding the development rules of the water flowing fracture zone during SBBM have been poorly investigated to date and need further exploration. At present, the height of the water flowing fracture zone in the mining process is also calculated according to the empirical formula in Regulations of coal mining under building, railways and water-bodies [21] (hereinafter referred to as the Regulations). In consideration of the particularity of the arrangement of working faces in the SBBM and the filling of gangue in the gob, whether the empirical formula in the Regulations is still valid in SBBM process needs further investigation.

Based on the SBBM technological characteristics, a new mechanical analysis method was established for calculating the height of the water flowing fracture zone in the overlying strata during the SBBM process, and the related mechanical properties of the development rules of the water flowing fracture zone were analyzed. Furthermore, the applicability of the Regulations was further judged. The present research results are of important significance to enhancing the recovery ratio of coal resources and protecting ecological environment.

\section{Engineering Geological Conditions and Field Measurement Results}

2.1. Engineering Geological Conditions. The Shaanbei coal mine is located in Yulin City, Shaanxi Province, China. The area of the mine field is $1.52 \mathrm{~km}^{2}$, and the recoverable coal reserve is 4.98 million tons. The surface of the mine field is covered by driftsands. The region of the mine belongs to arid and semi-arid areas with deficient water resource, sparse vegetation, and serious water loss, featured by typical semi-acrid and semi-desert continental climate. Moreover, the burial depth of coal seams is generally within $112.8-184.5 \mathrm{~m}$, which belongs to the shallow buried coal seam. The geological 
structure is simple and the coal quality is good, and long-wall mining is the main practiced method in the mine. The SBBM experimental region was to the north of the no. 10304 long-wall working face, with a mining length of about $150 \mathrm{~m}$ and a total experimental area of $19,500 \mathrm{~m}^{2}$. It is estimated that about 13,000 tons of coal in total can be recovered. The coal seam exhibits simple storage structures with slightly varying thicknesses and can be regarded as a nearly flat coal seam. The average thickness and burial depth of the coal seam are $5 \mathrm{~m}$ and $145 \mathrm{~m}$, respectively. A layer of the aquifer can be observed on the mining coal seam, with an average distance of $105 \mathrm{~m}$ away from the coal seam. This aquifer serves as the main potentially protected water resource for the mine. The top of the coal seam mainly consists of mudstone, fine sandstone, siltstone, sandy mudstone, fine sandstone, medium sandstone, siltstone, red clay, and driftsand from the bottom up. The aquifer is above the red clay layer. Figure 2 displays the detailed columnar illustration as well as physical and mechanical parameters of the coal seam.

In combination with the occurrence of corner coal pillars, the experimented region can be divided into two blocks for mining. The advancing length of each block was $72.5 \mathrm{~m}$, with a mining height of $5 \mathrm{~m}$; in addition, the protective coal pillar between the blocks was about $5 \mathrm{~m}$ in length, and the backfilling ratio of gangues in the gob was about $80 \%$. Figure 3 shows the geographic position of the mine and the related detailed arrangement in the SBMM working face.

\subsection{Field Measurement}

2.2.1. Test Method. During the field of the SBBM process, the height of the water flowing fracture zone was comprehensively determined by observation of washing fluid loss in the hole, core damage degree analysis, and drilling TV imaging detection. After mining and backfilling in the working face, an observation hole, denoted as hole F, was arranged on top of the working face to measure the height of the water flowing fracture zone. The detailed arrangement of the hole is shown in Figures 3 and 4 . Hole F was located at the center of the upper part of the mining region, $75 \mathrm{~m}$ away from the starting cut and $145 \mathrm{~m}$ in depth. The final level of the hole was in direct touch with the immediate roof. During the drilling process, the loss of the washing fluid, the core damage degree, and the development of fractures in the strata were used to comprehensively predict the height of the water flowing fracture zone.

2.2.2. Test Results. Figure 5 shows the variation in the loss of washing fluid in hole F, and Figure 6 displays the distribution of fractures in the strata in accordance with the drilling TV imaging results. At a drilling depth of $118.2 \mathrm{~m}$, the loss of washing fluid increased slightly from $0.28 \mathrm{~m}^{3} / \mathrm{h}$ to $2.12 \mathrm{~m}^{3} / \mathrm{h}$; meanwhile, the development width of fractures in the drilling was small, and no obvious cracks were observed, suggesting a complete lithology. Figure 6(a) shows the drilling TV image of the hole at a depth of $113.0 \mathrm{~m}$, indicating that the strata exhibited morphological integrity and no fractures. With increasing drilling depth, the loss of the washing fluid increased rapidly to $5.47 \mathrm{~m}^{3} / \mathrm{h}$; i.e., the loss of washing fluid varied significantly. According to the core observation results, the recovery ratio of core was $<50 \%$, and a lot of narrow fractures with different directions were developed in the core. Figure 6(b) shows the boundary at the top of the water flowing fracture zone. It can be observed that a vertical fracture began to appear at a depth of $118.2 \mathrm{~m}$. With increasing drilling depth, the loss of washing fluid in the hole varied slightly. Meanwhile, as shown in Figure 6(c), both the density of the vertical fractures and the damage range increased with increasing drilling depth. Therefore, it can be concluded that the development peak of the water flowing fracture zone was located at a depth of about $118.2 \mathrm{~m}$, and the height of the water flowing fracture zone was $26.8 \mathrm{~m}$.

\section{Short-Wall Block Backfill Mining (SBBM) Technique}

3.1. Coal Mining Method. The SBBM technique is mainly used for recycling corner coal pillars, industrial square pillars, and irregular coal blocks as well as the coal beneath buildings, railways, and water bodies, all of which are unsuitable or cannot be exploited by long-wall mining. The SBBM technique also exhibits a lot of advantages such as less investment, short operating period, and quick returns. Particularly, a set of short-wall mining equipment is only $20 \%$ of a set of longwall mining fully mechanized mining equipment in terms of cost. To be specific, based on the block caving mining technology, the gangues are filled in the gob as the backfill body after the mining of a block, and the next block is simultaneously mined. Accordingly, both the temporal continuity and spatial independence of mining and backfilling during the whole operating process can be ensured; i.e., SBBM can be regarded as a high-efficiency backfilling mining method characterized by mining/backfilling concurrence. The SBBM technique can greatly enhance the recovery ratio of the mine and prolong the mine's service life. Meanwhile, the filling of gangues that are piled up on the surface in the gob can reduce the damages to the environment and the enterprise's investment in environmental protection.

Figure 7 displays the structure of a typical SBBM system. Apparently, the system mainly consists of two subsystems, namely, gangue transportation system and coal transportation system. In the former transportation system, the transportation route of gangues is from the vertical feeding system, storage silo, main track roadway, auxiliary transportation roadway of SBBM, to the SBBM working face; in the latter transportation system, the coal in the working face is first transported to the haulage roadway of SBBM, then to the main haulage roadway and the main shaft, and finally to the ground surface.

3.2. Arrangement in the Working Face and Key Equipment. In the SBBM working face, four branch roadways were arranged for constituting a mining block, and the protective pillar was set between the two blocks. In each block, the pillars were extracted in retreat from top to bottom. During the recovery of coal pillars, the temporal coal pillar, with a width in the 


\begin{tabular}{|c|c|c|c|c|c|c|c|}
\hline Columnar & Lithology & $\begin{array}{l}\text { Thickness } \\
(h / m)\end{array}$ & $\begin{array}{c}\text { Density } \\
\gamma\left(\mathrm{kg} \cdot \mathrm{m}^{-3}\right)\end{array}$ & $\begin{array}{c}\text { Elastic modulus } \\
\text { E (GPa) }\end{array}$ & $\begin{array}{c}\text { Tensile strength } \\
\sigma(\mathrm{MPa})\end{array}$ & $\begin{array}{c}\text { Compressive strength } \\
\sigma^{\prime}(\mathrm{MPa})\end{array}$ & $\begin{array}{c}\text { Poisson's ratio } \\
\mu\end{array}$ \\
\hline & Driftsand & 50.0 & 1,800 & 0.79 & - & \begin{tabular}{|r|}
4.3 \\
\end{tabular} & 0.32 \\
\hline & Aquifer & - & - & - & - & - & - \\
\hline & Red clay & 8.0 & 1,600 & 0.02 & 0.02 & 10.4 & 0.30 \\
\hline 50 & Siltstone & 13.0 & 2,100 & 24.0 & 5.7 & 37.7 & 0.31 \\
\hline 58 & Medium sandstone & 25.0 & 2,200 & 29.2 & 8.0 & 41.2 & 0.29 \\
\hline 71 & Fine sandstone & 5.0 & 2,250 & 22.5 & 9.7 & 36.6 & 0.22 \\
\hline & Sandy mudstone & 17.0 & 1,950 & 13.3 & 4.5 & 25.5 & 0.24 \\
\hline 101 & Siltstone & 9.0 & 2,100 & 20.0 & 6.4 & 33.7 & 0.28 \\
\hline 118 & Fine sandstone & 15.0 & 2,250 & 16.5 & 8.9 & 38.4 & 0.22 \\
\hline & Mudstone & 3.0 & 1,650 & 11.2 & 2.7 & 18.4 & 0.25 \\
\hline & 5-2\# coal seam & 5.0 & 1,400 & 14.1 & 2.3 & 23.5 & 0.32 \\
\hline $150-$ & Medium sandstone & 7.0 & 2,250 & 28.5 & 4.9 & 39.0 & 0.26 \\
\hline
\end{tabular}

Figure 2: Columnar illustration and physical/mechanical properties of the coal seam.

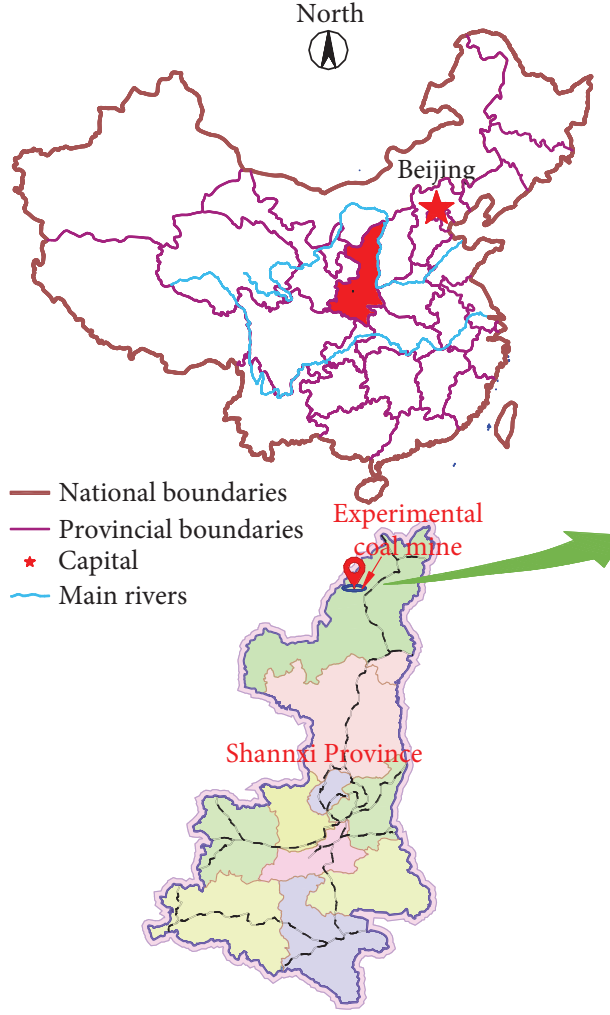

(a)

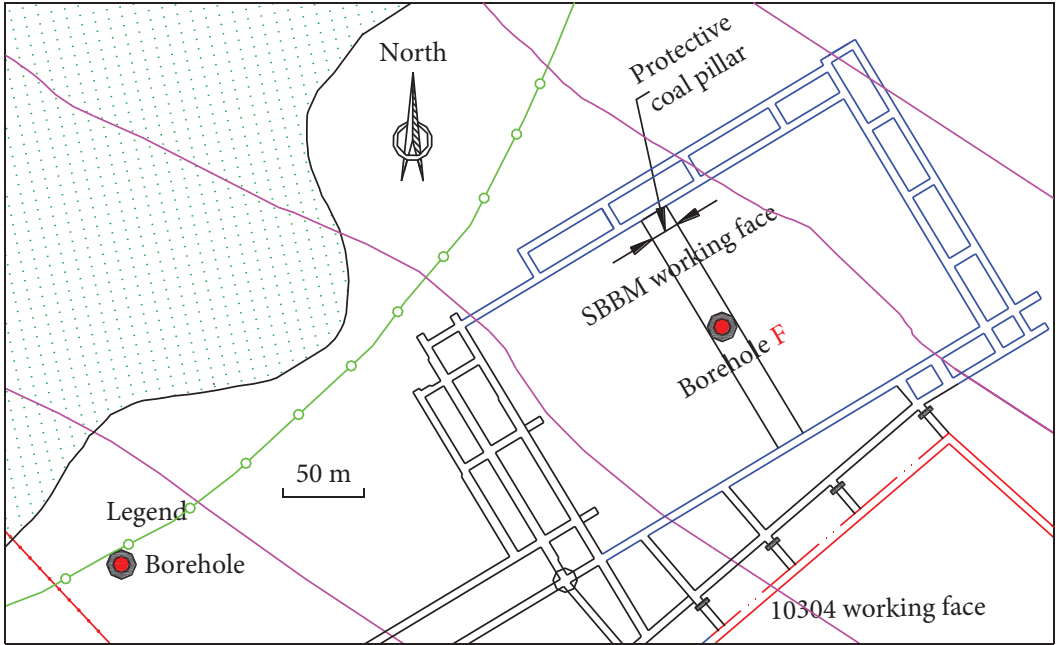

(b)

FIgURE 3: Geographic position of the mine and the detailed arrangement in the SBMM working face. (a) Geographical position of the mine; (b) detailed arrangement in the SBMM working face.

range $0.5-1.5 \mathrm{~m}$, was arranged between the wings. The length of the wing was no greater than $11 \mathrm{~m}$, and the width was about $3 \mathrm{~m}$. The intersection angle between the wing and the branch roadway was about $45^{\circ}$. After the recovery of a block, the gangues were filled into the wing, the branch roadway, and the joint roadway from top to bottom. The temporal coal pillars and the fire dams can act as a barrier to ensure that the filling ratio satisfies the design requirements.

SBBM technology mainly includes mining and backfilling. With regard to the mining technology, four track walking hydraulic supports were used and cooperated with the coal cutter for ensuring the safety in the coal cutting and loading. In more detail, four track walking hydraulic supports were divided into two sets: one set (the first two supports) was arranged in the branch roadway, and the other set (the latter two supports) was arranged in the joint roadway between the two adjacent branch roadways. Both the branch roadway and the joint roadway were about $5 \mathrm{~m}$ in width. With regard to the backfilling technology, two track walking hydraulic supports were arranged in the branch 


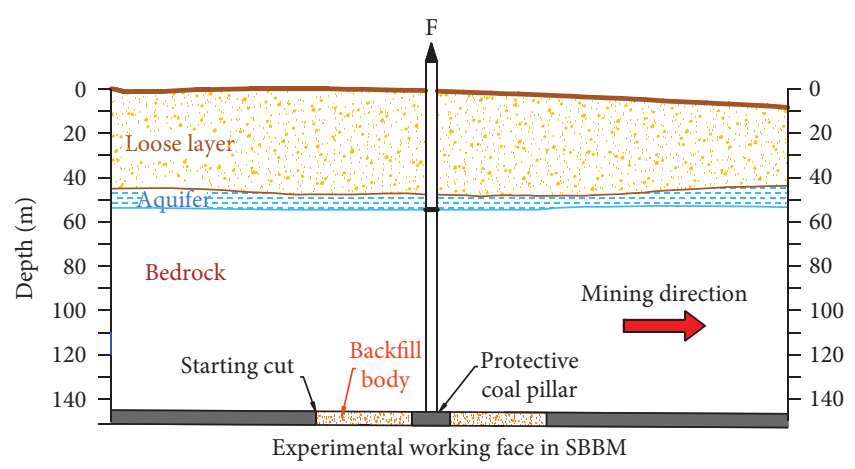

FIGURE 4: Illustration of the positions of the aquifer and the observation hole.

roadway; in cooperation with the waste throwing machine and the pushdozer, the gangues were filled in the gob and were in full contact with the roof. Accordingly, the gangues can serve as the permanent carrier and cooperated with the protective coal pillars between the blocks for supporting the overlying strata. Figure 8 displays the detailed arrangement of the SBBM working face.

\section{Mechanical Analysis of the Height of the Water Flowing Fracture Zone in SBBM}

According to SBBM technological characteristics, this study calculated the damage height of the overlying strata in the working face after mining and backfilling to determine the height of the water flowing fracture zone in the final overlying strata formed in the SBBM. As shown in Figure 9, a stratum above the coal seam (i.e., the $m^{\text {th }}$ stratum) was used as the object, and the overlying strata was simplified as the uniformly distributed load $q(m)$; meanwhile, in the lower strata that supported the rock beam, coal bodies (including both protective coal pillars and entity coal) and the backfill body were simplified as the Winkler elastic foundation. This study also assumed that $l_{a}$ denotes the length of each block (i.e., the

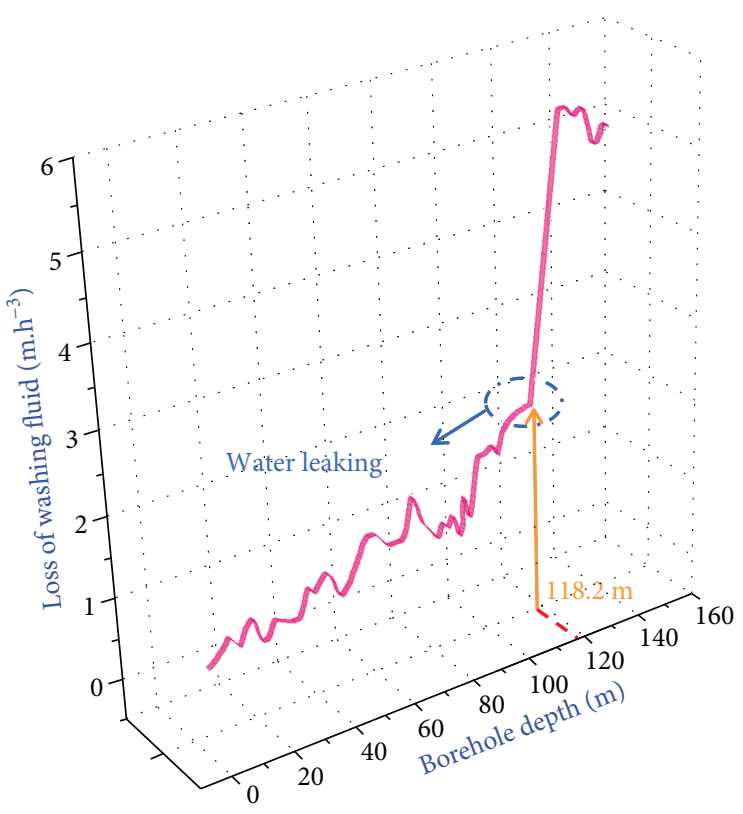

FIGURE 5: Relationship between the loss of washing fluid in the hole and the drilling depth.

length of the gob), $l_{b}$ denotes the width of the protective coal pillar between the blocks, $h_{k}$ denotes the mining height of the coal seam, $h_{1}, h_{2}, h_{3}, \ldots, h_{j}$ denote the thicknesses of various strata above the coal seam (total thickness of $m$ layers of strata above the coal rock and thus can be written as $H_{m}=$ $\left.\sum h_{m}(m=1,2,3, \ldots, j)\right), k_{a}$ denotes the coal's elastic foundation coefficient, $k_{b}$ denotes the backfill body's elastic foundation coefficient, and $k_{1}, k_{2}, \ldots k_{m-1}$ denote the elastic foundation coefficients of various strata beneath the $m^{\text {th }}$ stratum. Accordingly, the mechanical model of the overlying strata in the SBBM process based on elastic foundation beam was established.

The elastic foundation coefficients of the backfill body, the coal seam, and $(m-1)$ strata above the bedrock can be written as

$$
\left\{\begin{array}{l}
\frac{1}{k_{a}^{m}}=\frac{1}{k_{a}}+\frac{1}{k_{1}}+\frac{1}{k_{2}} \cdots+\frac{1}{k_{m-2}}+\frac{1}{k_{m-1}}, \quad \text { The combination of coal and strata } \\
\frac{1}{k_{b}^{m}}=\frac{1}{k_{b}}+\frac{1}{k_{1}}+\frac{1}{k_{2}} \cdots+\frac{1}{k_{m-2}}+\frac{1}{k_{m-1}}, \quad \text { The combination of backfilling bodies and strata. }
\end{array}\right.
$$

As shown in Figure 9, the model under that state exhibits a positively symmetrical structure. Therefore, to simplify the calculation, half of the model was selected for further analysis. Because of the difference in the number of blocks (denoted as $n$ ), the calculations were performed in the following two cases: (1) $n$ is an even number and (2) $n$ is an odd number.
4.1. Mechanical Model of the SBBM Working Face When $n$ Is an Even Number. When $n$ is an even number, the center of the protective pillar in the $n / 2^{\text {th }}$ block was set as the symmetry point, and the origin, denoted as $O$, was set at the junction between the protective coal pillar and the $n / 2^{\text {th }}$ block; then, the mechanical coordinate system was established by using 


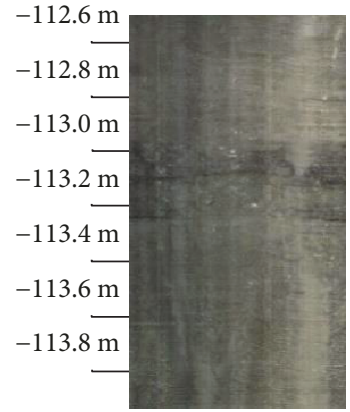

(a)

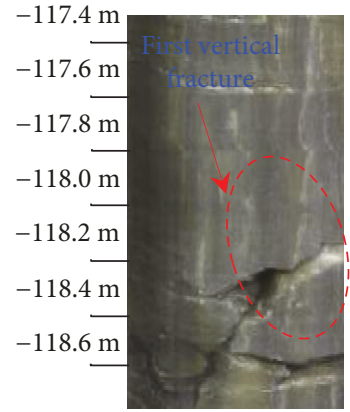

(b)

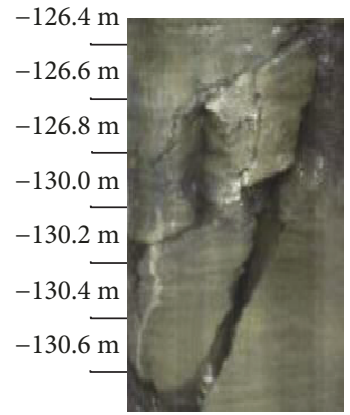

(c)

FIgure 6: Drilling TV imaging detection results of the distribution of fractures in the strata. (a) No fracture; (b) first vertical fracture; (c) fractured zone.

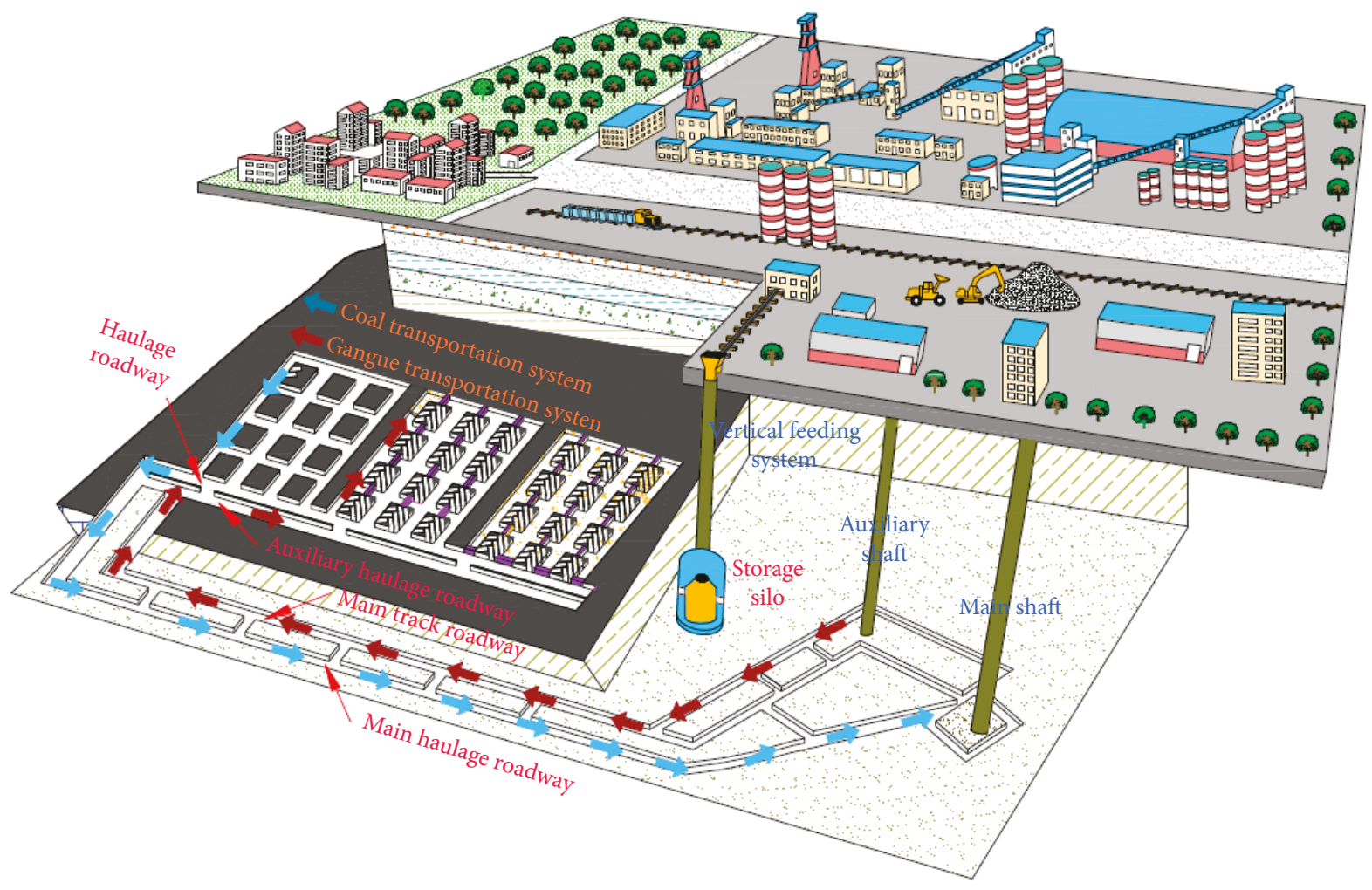

FIGURE 7: Illustration of the short-wall block backfill mining (SBBM) system.

the displacement function $w^{m}(x)$ as the unknown quantity, as shown in Figure 10.

According to Winkle's assumption for elastic foundations [22-24], the settlement amount of any point on the foundation surface is proportional to the pressure on the point per unit area. Actually, the foundation is simulated as a series of independent springs on the rigid foundation; next, when the pressure $(p)$ is applied on any point on the foundation surface, only the point sank by $w(x)$ because of the independence of the springs, while no sedimentation was observed at the other points. The following expression can be derived:

$$
p=k w(x)
$$

where $p$ denotes the pressure on the foundation per unit area, $w(x)$ denotes the subsidence of the foundation, and $k$ denotes the elastic foundation coefficient.

Based on the elastic foundation beam theory, the deflection of the rock beam, denoted as $w(x)$, and the applied load, denoted as $q$, satisfy the following differential equation of the deflection curve of the foundation beam:

$$
E I \frac{d^{4} w(x)}{d x^{4}}+p=q
$$

where EI denotes the flexural rigidity of the cross section of the rock beam. 


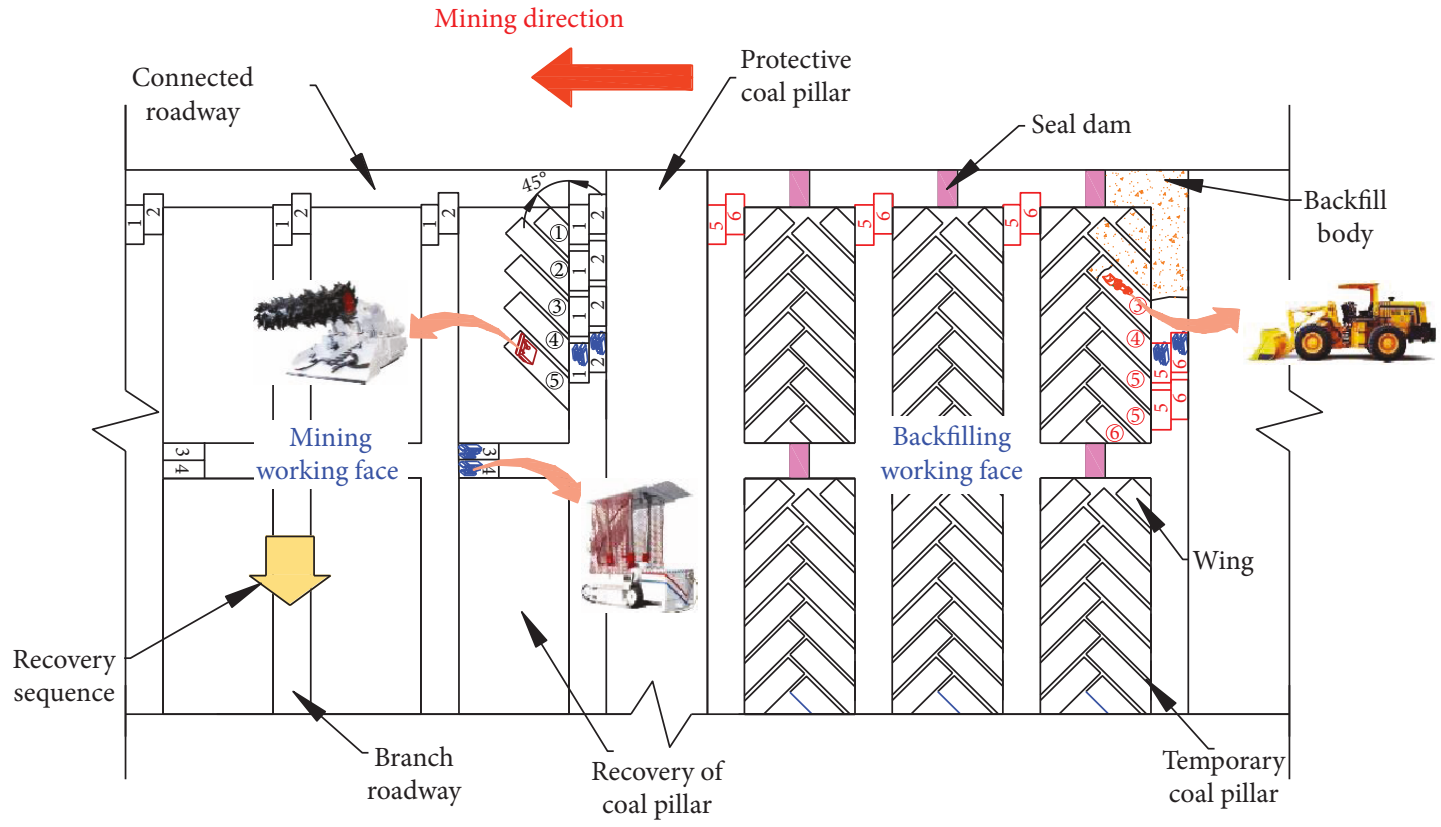

FIGURE 8: Arrangement in the SBBM working face and key equipment.

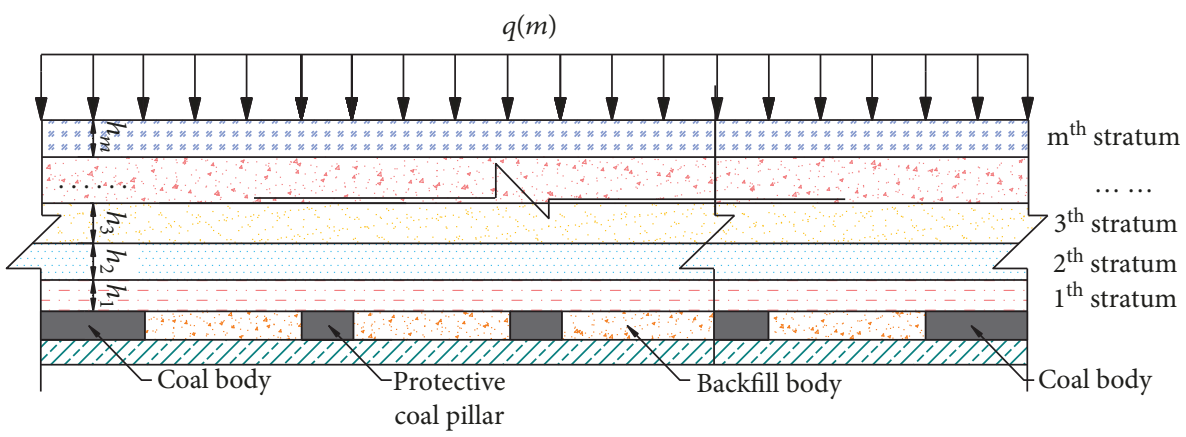

FIGURE 9: Basic environment state for mechanical analysis of SBBM stope.

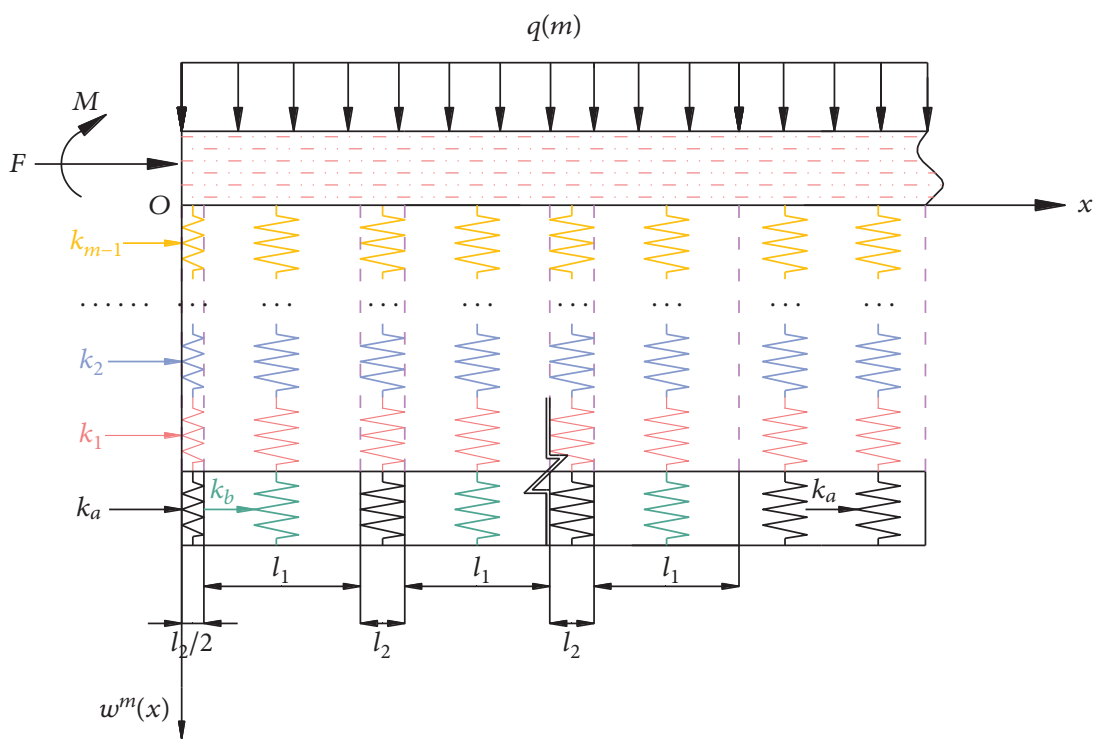

FIGURE 10: Established mechanical model of the $m^{\text {th }}$ stratum when $n$ is an even number. 
Therefore, by assuming the prearranged protective coal pillars in the SBBM working face, the backfill body and $(m-1)$ bed rock as independent springs, and the entity coal in the right part as semi-infinite elastic foundation, the $m^{\text {th }}$ rock beam can be treated as a semi-infinite long beam. By substituting (2) into (3), the deflection curve equations of the $m^{\text {th }}$ rock beam above the coal and the backfill body can be written as

$$
\begin{cases}\frac{d^{4} w_{1}^{m}(x)}{d x^{4}}+\frac{k_{a}^{m} w_{1}^{m}(x)}{E_{m} I_{m}}=\frac{q(m)}{E_{m} I_{m}}, & \left(-\frac{l_{b}}{2} \leq x \leq 0\right) \\ \frac{d^{4} w_{2}^{m}(x)}{d x^{4}}+\frac{k_{b}^{m} w_{2}^{m}(x)}{E_{m} I_{m}}=\frac{q(m)}{E_{m} I_{m}}, & \left(0 \leq x \leq l_{a}\right) \\ \frac{d^{4} w_{3}^{m}(x)}{d x^{4}}+\frac{k_{a}^{m} w_{3}^{m}(x)}{E_{m} I_{m}}=\frac{q(m)}{E_{m} I_{m}}, & \left(l_{a} \leq x \leq l_{a}+l_{b}\right) \\ \cdots & \left(\frac{n-2}{2} l_{a}+\frac{n-1}{2} l_{b} \leq x \leq \frac{n}{2} l_{a}+\frac{n-1}{2} l_{b}\right) \\ \frac{d^{4} w_{n}^{m}(x)}{d x^{4}}+\frac{k_{b}^{m} w_{n}^{m}(x)}{E_{m} I_{m}}=\frac{q(m)}{E_{m} I_{m}}, & \left(x>\frac{n}{2} l_{a}+\frac{n-1}{2} l_{b}\right) \\ \frac{d^{4} w_{n+1}^{m}(x)}{d x^{4}}+\frac{k_{a}^{m} w_{n+1}^{m}(x)}{E_{m} I_{m}}=\frac{q(m)}{E_{m} I_{m}}, & \end{cases}
$$

where $E_{m} I_{m}$ denotes the flexural rigidity of the cross section of the $m^{\text {th }}$ rock beam.
By setting the characteristic coefficients $\alpha=\sqrt[4]{k_{a}^{e} / 4 E_{m} I_{m}}$ and $\beta=\sqrt[4]{k_{b}^{e} / 4 E_{m} I_{m}}$ and solving (4), the deflection curve equations of the $m^{\text {th }}$ rock beam can be written as

$$
w^{m}(x)=\left\{\begin{array}{ccc}
w_{1}^{m}(x)=e^{\alpha x}\left(a_{1} \cos \alpha x+b_{1} \sin \alpha x\right)+e^{-\alpha x}\left(c_{1} \cos \alpha x+d_{1} \sin \alpha x\right)+\frac{q(m)}{k_{a}^{m}} & \left(-\frac{l_{b}}{2} \leq x \leq 0\right) \\
w_{2}^{m}(x)=e^{\beta x}\left(a_{2} \cos \beta x+b_{2} \sin \beta x\right)+e^{-\beta x}\left(c_{2} \cos \beta x+d_{2} \sin \beta x\right)+\frac{q(m)}{k_{b}^{m}} & \left(0 \leq x \leq l_{a}\right) \\
w_{3}^{m}(x)=e^{\alpha x}\left(a_{3} \cos \alpha x+b_{3} \sin \alpha x\right)+e^{-\alpha x}\left(c_{3} \cos \alpha x+d_{3} \sin \alpha x\right)+\frac{q(m)}{k_{a}^{m}} & \left(l_{a} \leq x \leq l_{a}+l_{b}\right) \\
\cdots & \\
w_{n}^{m}(x)=e^{\beta x}\left(a_{n} \cos \beta x+b_{n} \sin \beta x\right)+e^{-\beta x}\left(c_{n} \cos \beta x+d_{n} \sin \beta x\right)+\frac{q(m)}{k_{b}^{m}} & \left(\frac{n-2}{2} l_{a}+\frac{n-1}{2} l_{b} \leq x \leq \frac{n}{2} l_{a}+\frac{n-1}{2} l_{b}\right) \\
w_{n+1}^{m}(x)=e^{\alpha x}\left(a_{n+1} \cos \alpha x+b_{n+1} \sin \alpha x\right)+e^{-\alpha x}\left(c_{n+1} \cos \alpha x+d_{n+1} \sin \alpha x\right)+\frac{q(m)}{k_{a}^{m}} & \left(x>\frac{n}{2} l_{a}+\frac{n-1}{2} l_{b}\right) .
\end{array}\right.
$$

The rotation angle, bending moment, and shearing force of any cross section in the $m^{\text {th }}$ rock beam can be written as

$$
\left\{\begin{array}{l}
\theta^{m}(x)=\frac{d w^{m}(x)}{d x} \\
M^{m}(x)=-E_{m} I_{m} \frac{d \theta^{m}(x)}{d x}=-E I \frac{d^{2} w^{m}(x)}{d x^{2}} \\
Q^{m}(x)=\frac{d M^{m}(x)}{d x}=-E I \frac{d^{3} w^{m}(x)}{d x^{3}} .
\end{array}\right.
$$

The elastic foundation coefficient of the backfill body and the backfill ratio satisfy the following expression [25]:

$$
k_{c}=\frac{\sigma_{0}}{h_{k}(1-\varphi)},
$$

where $\sigma_{0}$ and $\varphi$ denote the stress of the primary rock and the backfill ratio $(0<\varphi<1)$, respectively.

Because of the symmetrical model structure and load, the deflection curve and the bending-moment curve of the rock 
beam are symmetrical, and the rotation-angle curve and the shearing-force curve are anti-symmetrical; accordingly, the rotation angle and shearing force at the symmetrical point equaled to 0 . Furthermore, according to the qualitative analysis results of the semi-infinite long beam as shown in Figure 10 , when $x \rightarrow+\infty$, then $w \rightarrow 0$ and $\theta \rightarrow 0$. Based on the above analysis, the boundary conditions of the beam can be described as

$$
\begin{cases}\theta_{1}^{m}\left(-\frac{l_{b}}{2}\right)=0, & Q_{1}^{m}\left(-\frac{l_{b}}{2}\right)=0 \\ \theta_{n}^{m}(+\infty)=0, & w_{n}^{m}(+\infty)=0 .\end{cases}
$$

The continuity condition can then be described as follows. The deflection, bending moment, rotation angle, and shearing force at the connection point among the protective coal pillar, the gob, and the entity coal equaled to each other.
By substituting the boundary conditions and continuity condition into (5), $a_{1}, b_{1}, c_{1}, d_{1}, a_{2}, b_{2}, c_{2}, d_{2}, \ldots, a_{n+1}, b_{n+1}$, $c_{n+1}$, and $d_{n+1}$ can be solved; i.e., with these parameters, the bending subsidence equation and the bending-moment equation of the $m^{\text {th }}$ rock beam, denoted as $w^{m}(x)$ and $M^{m}(x)$, respectively, can be solved.

4.2. Mechanical Model of the SBBM Working Face When $n$ Is an Odd Number. Figure 11 displays the established mechanical model of the $m^{\text {th }}$ stratum, when $n$ is an odd number. The center of the $(n+1 / 2)^{\text {th }}$ block was selected as the symmetry point, and the junction between the $(n+1 / 2)^{\text {th }}$ block and the protective coal pillar was set as the origin $(O)$. Next, the mechanical calculation model of the $m^{\text {th }}$ stratum was established by using the displacement function $w^{m}(x)$ as the unknown quantity.

According to the elastic foundation beam theory, the general formula of the deflection curve of the $m^{\text {th }}$ stratum in the overlying rock can be written as

$$
w^{m \prime}(x)=\left\{\begin{array}{l}
w_{1}^{m^{\prime}}(x)=e^{\beta x}\left(a_{1}{ }^{\prime} \cos \beta x+b_{1}{ }^{\prime} \sin \beta x\right)+e^{-\beta x}\left(c_{1}{ }^{\prime} \cos \beta x+d_{1}{ }^{\prime} \sin \beta x\right)+\frac{q(m)}{k_{b}^{m}} \quad\left(-\frac{l_{a}}{2} \leq x \leq 0\right) \\
w_{2}^{m^{\prime}}(x)=e^{\alpha x}\left(a_{2}{ }^{\prime} \cos \alpha x+b_{2}{ }^{\prime} \sin \alpha x\right)+e^{-\alpha x}\left(c_{2}{ }^{\prime} \cos \alpha x+d_{2}{ }^{\prime} \sin \alpha x\right)+\frac{q(m)}{k_{a}^{m}} \quad\left(0 \leq x \leq l_{b}\right) \\
w^{m^{\prime}}(x)=e^{\beta x}\left(a_{3}{ }^{\prime} \cos \beta x+b_{3}{ }^{\prime} \sin \beta x\right)+e^{-\beta x}\left(c_{3}{ }^{\prime} \cos \beta x+d_{4}{ }^{\prime} \sin \beta x\right)+\frac{q(m)}{k_{b}^{m}} \quad\left(l_{b} \leq x \leq l_{a}+l_{b}\right) \\
w_{n}^{m^{\prime}}(x)=e^{\beta x}\left(a_{n}{ }^{\prime} \cos \beta x+b_{n}{ }^{\prime} \sin \beta x\right)+e^{-\beta x}\left(c_{n}{ }^{\prime} \cos \beta x+d_{n}{ }^{\prime} \sin \beta x\right)+\frac{q(m)}{k_{b}^{m}} \quad\left(\frac{n-2}{2} l_{a}+\frac{n-1}{2} l_{b} \leq x \leq \frac{n}{2} l_{a}+\frac{n-1}{2} l_{b}\right) \\
w_{n+1}^{m}{ }^{\prime}(x)=e^{\alpha x}\left(a_{n+1}{ }^{\prime} \cos \alpha x+b_{n+1}{ }^{\prime} \sin \alpha x\right)+e^{-\alpha x}\left(c_{n+1}{ }^{\prime} \cos \alpha x+d_{n+1}{ }^{\prime} \sin \alpha x\right)+\frac{q(m)}{k_{a}^{m}} \quad\left(x>\frac{n}{2} l_{a}+\frac{n-1}{2} l_{b}\right) .
\end{array}\right.
$$

The boundary conditions of the model can be described as

$$
\begin{cases}\theta_{1}^{m^{\prime}}\left(-\frac{l_{a}}{2}\right)=0, & Q_{1}^{m^{\prime}}\left(-\frac{l_{a}}{2}\right)=0 \\ \theta_{n+1}^{m}{ }^{\prime}(+\infty)=0, & w_{n+1}^{m}{ }^{\prime}(+\infty)=0\end{cases}
$$

Similarly, the continuity condition can be described as follows. The deflection, bending moment, rotation angle, and shearing force at the connection point among the protective coal pillar, the gob, and the entity coal equaled to each other.

Similarly, by substituting the boundary conditions and continuity condition into (9), $a_{1}{ }^{\prime}, b_{1}{ }^{\prime}, c_{1}{ }^{\prime}, d_{1}{ }^{\prime}, a_{2}{ }^{\prime}, b_{2}{ }^{\prime}, c_{2}{ }^{\prime}$, $d_{2}{ }^{\prime}, \ldots, a_{n+1}{ }^{\prime}, b_{n+1}{ }^{\prime}, c_{n+1}{ }^{\prime}$, and $d_{n+1}{ }^{\prime}$ can be solved; i.e., the deflection equation and the bending-moment equation of the $m^{\text {th }}$ rock beam, denoted as $w^{m^{\prime}}(x)$ and $M^{m^{\prime}}(x)$, respectively, can be solved.
4.3. Calculation of the Height of the Water Flowing Fracture Zone. According to mechanics of materials, the maximum tensile stress of the rock beam can be calculated as

$$
\sigma_{\max }^{m}=\left|\frac{6 M_{\max }^{m}}{h_{m}^{2}}\right|,
$$

where $\sigma^{m}{ }_{\max }$ and $M^{m}{ }_{\max }$ denote the maximum stress of the $m^{\text {th }}$ strata in the overlying rock and the maximum bending moment of the $m^{\text {th }}$ strata, respectively.

According to the first strength theory, the fracturing of the rock beam should satisfy the following expression:

$$
\sigma_{\max }^{m} \geq\left[\sigma_{m}\right]
$$

where $\left[\sigma_{m}\right]$ denotes the tensile strength of the $m^{\text {th }}$ stratum in the overlying rock. 


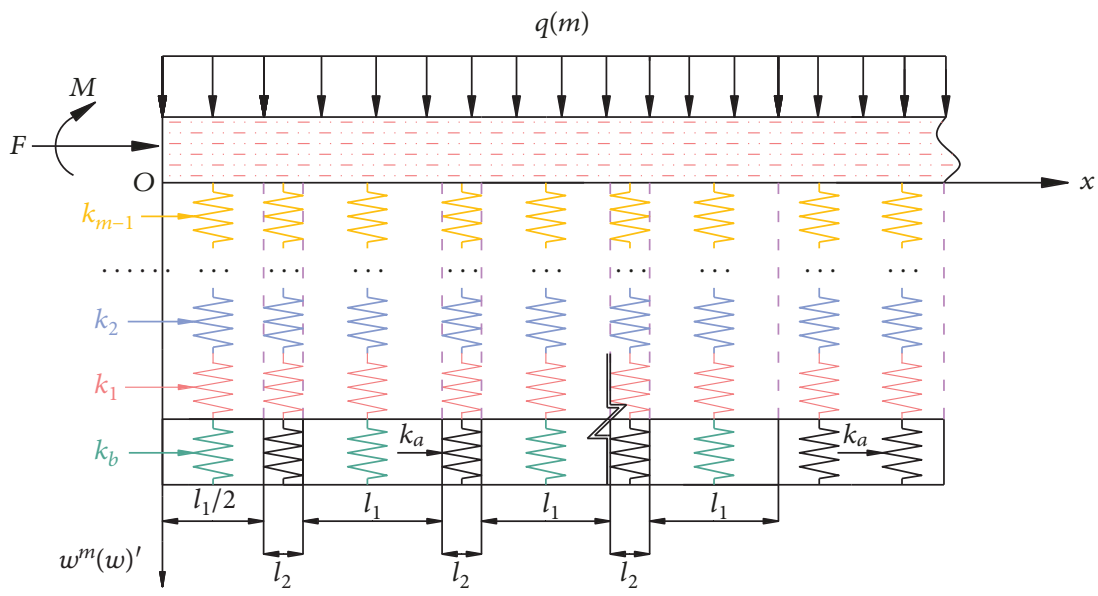

FIgURE 11: Established mechanical model of the $m^{\text {th }}$ stratum when $n$ is an odd number.

If (12) can be satisfied, the stratum is not destroyed, and the water flowing fracture zone is produced; in contrast, the fractures are formed. First, the 1st stratum above the coal seam is analyzed; if the stratum satisfies (12), the adjacent upper stratum is verified, and the calculation stops until the stratum is not fractured. The height of the water flowing fracture zone equals to the superposition of the thicknesses of various fractured strata:

$$
H=h_{1}+h_{2}+h_{3}+\cdots .
$$

The detailed engineering parameters and the mechanical parameters of various strata, as displayed in Figures 2 and 3, were substituted into the mechanical model of the SBBM working face. Through calculation, the height of the water flowing fracture zone was determined as $27.0 \mathrm{~m}$, and the top of the water flowing fracture zone was about $68.0 \mathrm{~m}$ away from the aquifer; i.e., the water flowing fractures did not develop towards the aquifer.

\section{Discussion}

Currently, the height of the water flowing fracture zone was mainly predicted according to the related formula in the Regulations; however, this prediction formula was concluded in the early 1980s through regression statistics based on limited field measurement data of some mines in China [20]. Because of the specificity of arrangement in the SBBM working face and the filling of gangues in the gob, SBBM differs from long-wall mining in roof management, thereby leading to different rules and mechanisms of mine pressure and fracture development. Whether the empirical formula in the Regulation concluded based on the measured data during long-wall mining is applicable for the calculation of the height of the water flowing fracture zone in SBBM still needs further discussion.

5.1. Contrastive Analysis of the Height of the Water Flowing Fracture Zone. According to the mechanical parameters of various strata in Figure 2, the mean compressive strength of the roof was about $28.4 \mathrm{MPa}$, suggesting that the strata can be regarded as medium hard strata. In accordance with the prediction formula in Appendix 7 of the Regulations, the height of the water flowing fracture zone can be calculated as

$$
H=\frac{100 M}{1.6 M+3.6}+5.6
$$

where $H$ and $M$ denote the height of the water flowing fracture zone and the mining height, respectively.

As listed in Table 1, the calculated height of the water flowing fracture zone according to the formula in the Regulations is $48.7 \mathrm{~m}$, and the calculated results based on the established mechanical model is $27.0 \mathrm{~m}$, while the field measured height of the water flowing fracture zone is $26.8 \mathrm{~m}$; i.e., the water flowing fracture zone did not develop towards the aquifer. Apparently, the prediction value according to the formula in the Regulations deviates greatly from the measured results, suggesting that the prediction formula is no longer applicable to the calculation of the height of the water flowing fracture zone in the SBBM; in contrast, the calculated height by the established mechanical model fits well with the measured result, validating high reliability of the proposed calculation model.

5.2. Analysis of Mining Upper Limit. For preventing and controlling the loss of water resources after the mining in the working face, the Regulations specifies that for the preset water proof coal pillars in the mining of the coal seam beneath the aquifer, not only should the development height of the water flowing fracture zone be calculated but also the thickness of the protective layer should be considered. Therefore, as shown in Figure 12, the minimum thickness of the water proof coal pillar allowed in mining beneath the aquifer (i.e., the minimum distance between the mining coal seam and the aquifer), denoted as $H_{f}$, should be equal to the height of the water flowing fracture zone $(H)$ and the thickness of the protective layer $\left(H_{b}\right)$ :

$$
H_{f}=H+H_{b} .
$$


TABLE 1: Contrastive analysis of the calculated and measured height of water flowing fracture zone.

\begin{tabular}{lccc}
\hline \multirow{2}{*}{$\begin{array}{l}\text { Height of the water flowing } \\
\text { fracture zone }\end{array}$} & Measured results of & Prediction results according to the & Calculation results based on the \\
& hole F & Regulations & mechanical model \\
& $26.8 \mathrm{~m}$ & $48.7 \mathrm{~m}$ & $27.0 \mathrm{~m}$ \\
\hline
\end{tabular}

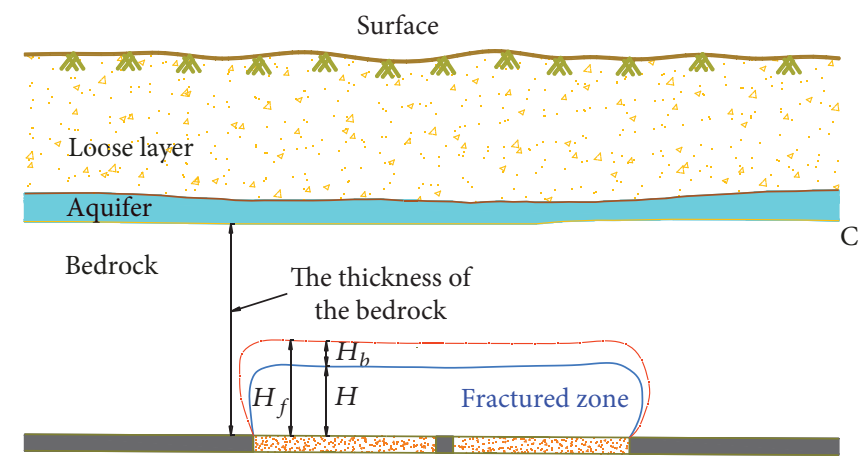

FIGURE 12: Relationship between the thickness of the protective layer and the height of the water flowing fracture zone.

According to the provisions in the Regulation, the thickness of the protective layer can be determined by considering the structural characteristics and mechanical properties of the coal rock in the SBBM working face:

$$
H_{b}=3 M
$$

By substituting the related data into (15) and (16), in combination with the mechanical theoretical analysis and field measured height of the water flowing fracture zone, the minimum thickness of the waterproof coal pillar allowed on the mining site $\left(H_{f}\right)$ was determined as about $42 \mathrm{~m}$, while the distance between the mining coal seam and the aquifer was $95 \mathrm{~m}$. The thickness of the bed rock far exceeded the allowable minimum thickness of the waterproof coal pillar, indicating that the aquifer was not affected by the mining activities in the SBBM. In addition, the gangues were filled in the gob as the backfill body, which then cooperated with the coal pillar to bear the load of the overlying strata, thereby effectively decreasing the height of the mining-induced water flowing fracture zone. Meanwhile, the mining upper limit of the coal seam and the resulting coal recovery ratio can be enhanced, thus achieving the goal of water-preserved mining beneath the acquirer.

\section{Conclusions}

(1) This study proposed the SBBM method for the recovery of corner coal pillars, industrial square pillars, and irregular blocks beneath the aquifer and simultaneously addressed the problem of massive stacking of gangues on the earth's surface. In addition, by measuring the loss of washing fluid, core damage analysis, and drilling TV imaging detection, the height of the water flowing fracture zone in the SBBM working face was determined as $26.8 \mathrm{~m}$.
(2) Based on the technological characteristics of SBBM and the theory of elastic foundation beam, a mechanical model for the calculation of the height of the water flowing fracture zone in the overlying strata using SBBM was established. The calculated height of the water flowing fracture zone according to the mechanical mode $(27.0 \mathrm{~m})$ almost equals to the measured value $(26.8 \mathrm{~m})$, thus verifying the accuracy of the proposed mechanical model.

(3) The distance between the coal seam and the aquifer was $95 \mathrm{~m}$, which far exceeds the allowable minimum thickness of the protective coal pillar $(42 \mathrm{~m})$. Therefore, it can be concluded that the aquifer was not affected by mining activities, and simultaneously the mining upper limit of coal seam as well as the recovery ratio of coal can be enhanced in the SBBM.

(4) The calculated height of the water flowing fracture zone according to the prediction formula in the Regulations $(48.7 \mathrm{~m})$ differs greatly from the measured value $(26.8 \mathrm{~m})$ and the calculated value according to the established mechanical model $(27 \mathrm{~m})$. Furthermore, in contrast with the caving mining method, the SBBM method used the gangues as the backfilling materials and filled them in the gob. The gangues cooperated with the coal pillars for bearing the load of the overlying strata, which can effectively reduce the height of the mining-induced water flowing fracture zone, avoid mining-induced damages on the aquifer, and thus achieve the goal of water-preserved mining beneath the aquifer.

\section{Data Availability}

The data used to support the findings of this study are available from the corresponding author upon request.

\section{Conflicts of Interest}

The authors declare have no conflict of interest.

\section{Acknowledgments}

This study was supported jointly by the National Key Basic Research Program of China (2015CB251600), the National Natural Science Foundation of China (51874284), and Fundamental Research Funds for the Central Universities (2018ZDPY04). 


\section{References}

[1] V. Palchik, "Localization of mining-induced horizontal fractures along rock layer interfaces in overburden: field measurements and prediction," Environmental Geology, vol. 48, no. 1, pp. 68-80, 2005.

[2] R. Singh, P. K. Mandal, A. K. Singh, R. Kumar, J. Maiti, and A. K. Ghosh, "Upshot of strata movement during underground mining of a thick coal seam below hilly terrain," International Journal of Rock Mechanics and Mining Sciences, vol. 45, no. 1, pp. 29-46, 2008.

[3] G. Fan and D. Zhang, "Mechanisms of aquifer protection in underground coal mining," Mine Water and the Environment, vol. 34, no. 1, pp. 95-104, 2015.

[4] J. Liu, W. Sui, and Q. Zhao, "Environmentally sustainable mining: a case study of intermittent cut-and-fill mining under sand aquifers," Environmental Earth Sciences, vol. 76, no. 16, p. 562, 2017.

[5] J. Zhang and B. Shen, "Coal mining under aquifers in China: a case study," International Journal of Rock Mechanics and Mining Sciences, vol. 41, no. 4, pp. 629-639, 2004.

[6] S. Liu, W. Li, and Q. Wang, "Height of the water-flowing fractured zone of the Jurassic coal seam in northwestern China," Mine Water and the Environment, vol. 37, no. 2, pp. 312321, 2018.

[7] J. Zhang, B. Li, N. Zhou, and Q. Zhang, "Application of solid backfilling to reduce hard-roof caving and longwall coal face burst potential," International Journal of Rock Mechanics and Mining Sciences, vol. 88, pp. 197-205, 2016.

[8] W. Zhang, D. S. Zhang, L. X. Wu, and H. Z. Wang, "On-site radon detection of mining-induced fractures from overlying strata to the surface: a case study of the Baoshan coal mine in China," Energies, vol. 7, no. 12, pp. 8483-8507, 2014.

[9] D. Zhang, G. Fan, Y. Liu, and L. Ma, "Field trials of aquifer protection in longwall mining of shallow coal seams in China," International Journal of Rock Mechanics and Mining Sciences, vol. 47, no. 6, pp. 908-914, 2010.

[10] D. Zhang, G. Fan, L. Ma, and X. Wang, "Aquifer protection during longwall mining of shallow coal seams: a case study in the Shendong coalfield of China," International Journal of Coal Geology, vol. 86, no. 2-3, pp. 190-196, 2011.

[11] B. Jiang, L. Wang, Y. Lu, X. Sun, and G. Jin, "Ground pressure and overlying strata structure for a repeated mining face of residual coal after room and pillar mining," International Journal of Mining Science and Technology, vol. 26, no. 4, pp. 645652, 2016.

[12] J. X. Zhang, P. Huang, Q. Zhang, M. LI, and Z. W. Chen, "Stability and control of room mining coal pillars-taking room mining coal pillars of solid backfill recovery as an example," Journal of Central South University, vol. 24, no. 5, pp. 1121-1132, 2017.

[13] J. Sun and X. Miao, "Water-isolating capacity of an inclined coal seam floor based on the theory of water-resistant key strata," Mine Water and the Environment, vol. 36, no. 2, pp. 310-322, 2017.

[14] X. X. Miao, A. Wang, Y. J. Sun, L. G. Wang, and H. Pu, "Research on basic theory of mining with water resources protection and its application to arid and semi-arid mining areas," Chinese Journal of Rock Mechanics and Engineering, vol. 28, no. 2, pp. 217-227, 2009.

[15] J. L. Xu, W. B. Zhu, and X. Z. Wang, "Study on water-inrush mechanism and prevention during coal mining under unconsolidated confined aquifer," Journal of Mining \& Safety Engineering, vol. 28, no. 3, pp. 333-339, 2011.

[16] X. Z. Wang, J. L. Xu, and W. B. Zhu, "Influence of primary key stratum structure stability on evolution of water flowing fracture," Journal of China Coal Society, vol. 37, no. 4, pp. 606-612, 2012.

[17] J. L. Xu, X. Z. Wang, W. T. Liu, and Z. G. Wang, "Effects of primary key stratum location on height of water flowing fracture zone," Chinese Journal of Rock Mechanics \& Engineering, vol. 28, no. 2, pp. 381-385, 2009.

[18] M. P. Zhou, Research on Contssssssinuous Mining Methods and Rock Control Technology, China University of Mining \& Technology, Xuzhou, China, 2014.

[19] M. P. Zhou, S. G. Cao, and X. J. Jiang, "The law of rock pressure in the stope with blocking mining by the continuous miner," Journal of Mining \& Safety Engineering, vol. 31, no. 3, pp. 413-417, 2014.

[20] S. G. Cao, Y. Cao, and H. J. Jiang, "Research on catastrophe instability mechanism of section coal pillars in block mining," Journal of Mining \& Safety Engineering, vol. 31, no. 6, pp. $907-$ 913, 2014

[21] State Bureau of Coal Industry, Regulations of Coal Mining under Building, Railways and Wayer-Bodies, China Coal Industry Publishing House, Beijing, China, 2000.

[22] B. Ozturk and S. B. Coskun, "The Homotopy perturbation method for free vibration analysis of beam on elastic foundation," Structural Engineering and Mechanics, vol. 37, no. 4, pp. 415-425, 2011.

[23] Y. X. Yu, R. B. Huang, and B. Q. Wang, "Analysis on limit equilibrium zone of coal pillar in mining roadway based on mechanical model of elastic foundation beam," Journal of Engineering Mechanics, vol. 142, no. 4, p. 04016009, 2016.

[24] J. O. Kim, K. S. Lee, and J. W. Lee, "Beam stability on an elastic foundation subjected to distributed follower force," Journal of Mechanical Science and Technology, vol. 22, no. 12, pp. 23862392, 2008.

[25] B. F. An, J. X. Zhang, M. Li, and P. Huang, "Stability of pillars in backfilling mining working face to recover room mining standing pillars," Journal of Mining \& Safety Engineering, vol. 33, no. 2, pp. 238-243, 2016. 

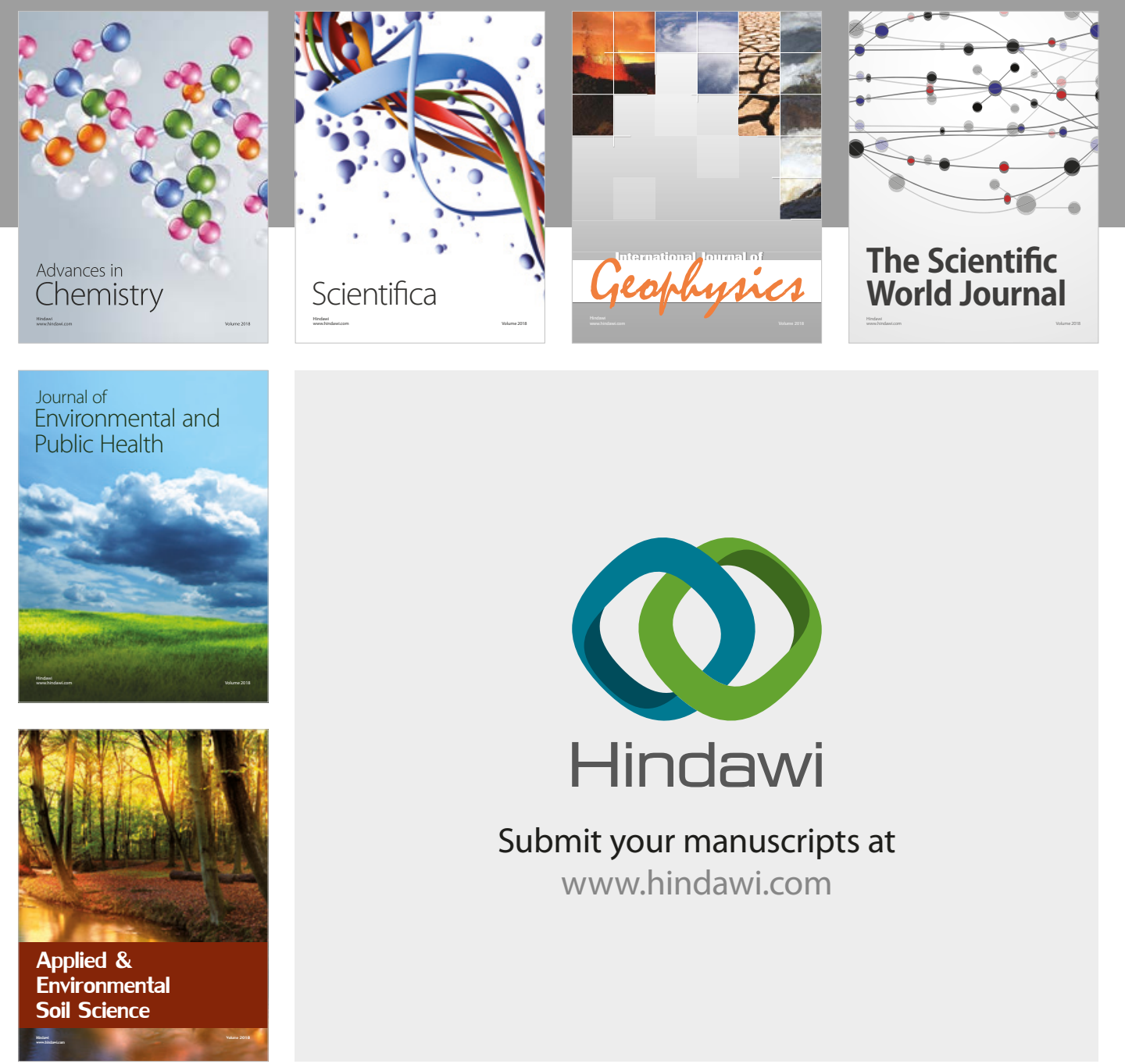

The Scientific

\section{World Journal}
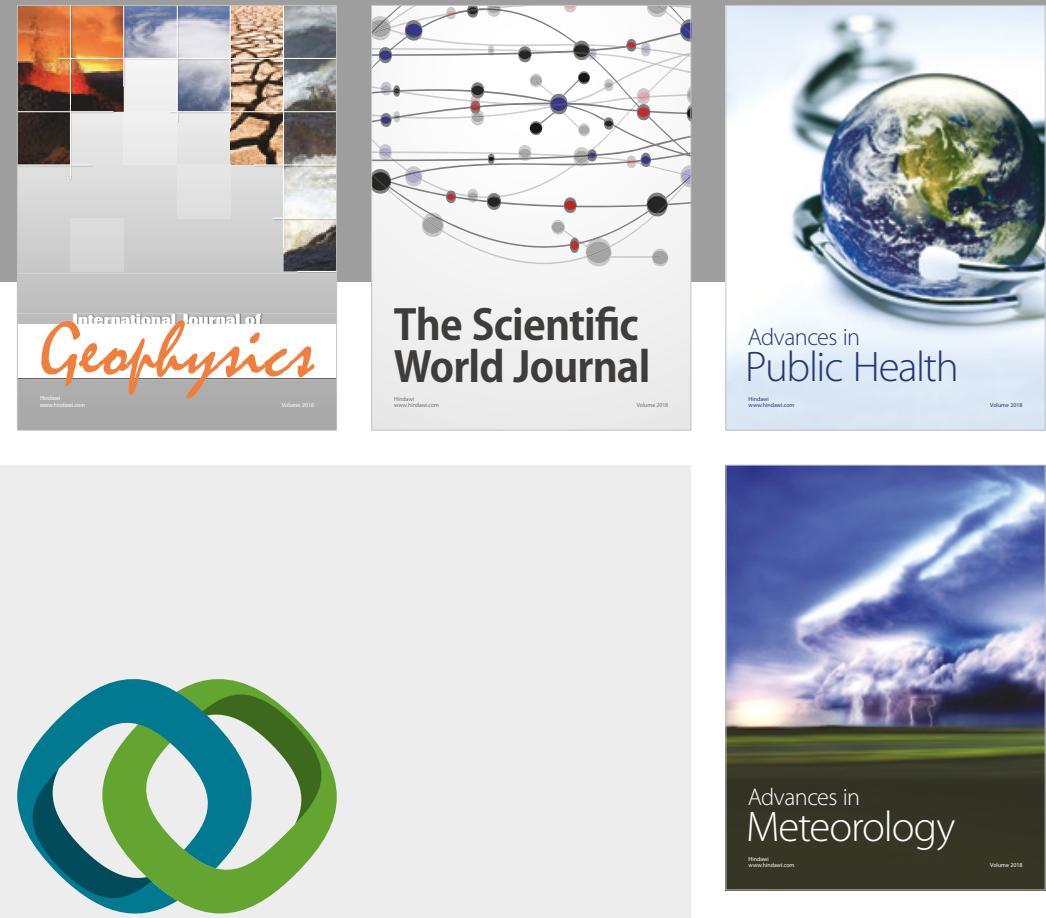

Advan

Public Health

\section{Hindawi}

Submit your manuscripts at

www.hindawi.com
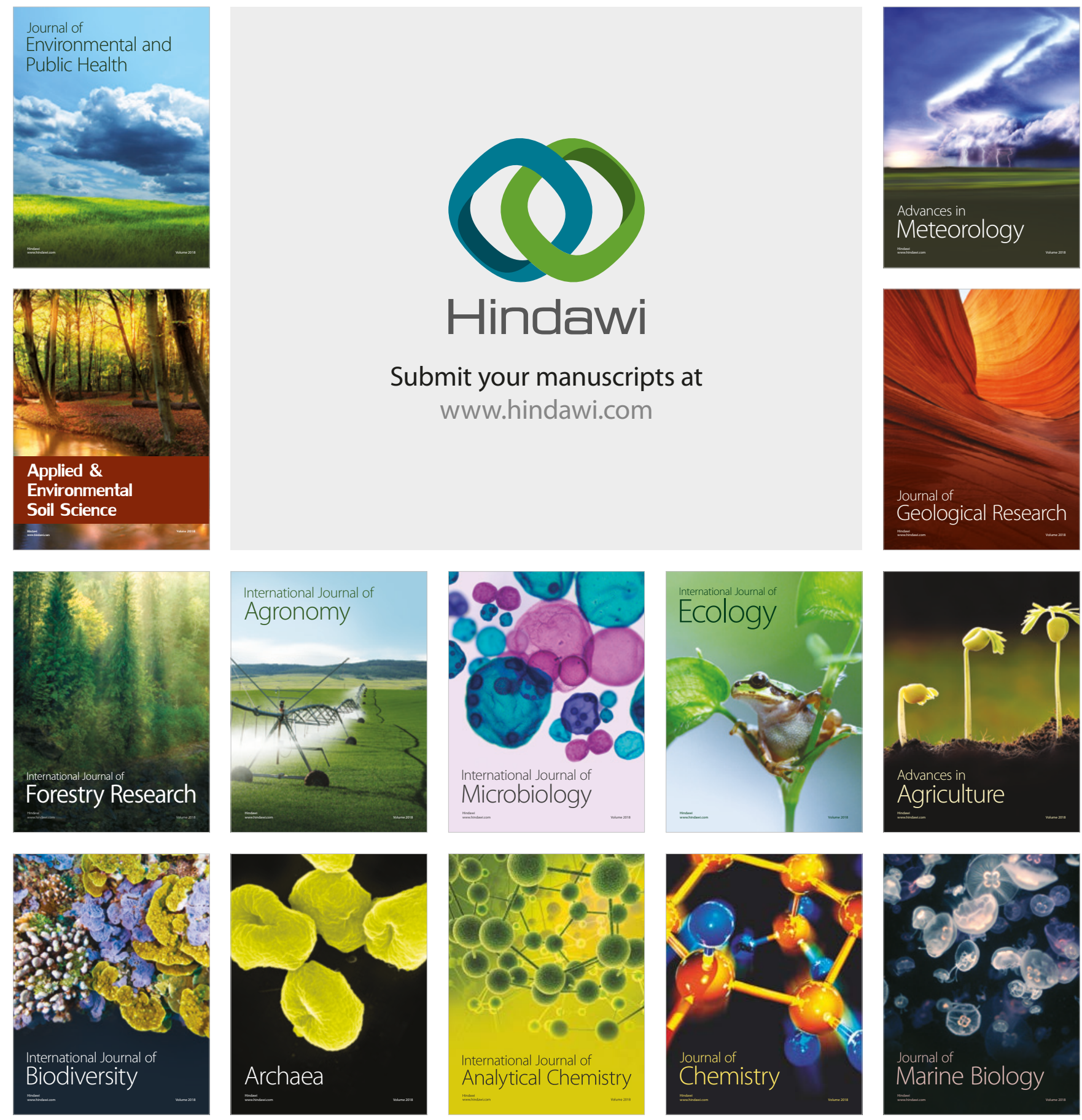